SSRIs have been described to produce EPS and TD (Arya, 1994; Coulter \& Pillans, 1995). If brain damage proves to be a common factor it might be as well to bear this in mind when prescribing SSRIs.

ARYA, D. K. (1994) Extrapyramidal symptoms with selective serotonin uptake inhibitors. British Journal of Psychiatry, 165, 728-733.

Coulter, M. \& Plllans, P. I. (1995) Fluoxetine and extrapyramidal side effects. American Journal of Psychiatry, 152, 122-125.

Pourchier, E., BARUCH, P., BOUCHARD, R. H., et al (1995)

Neuroleptic associated tardive dyskinesias in young people with psychoses. British Journal of Psychiatry, 166, 768-772.

Northern General Hospital

A. Al-Adwan Sheffield S5 7AU

\section{Psychosurgery for obsessional disorder}

StR: The reviews by Piccinelli et al (1995) and James \& Blackburn (1995) summarise the current state of knowledge of the outcome of treatment of obsessional disorder by pharmacological and cognitive therapeutic methods. The third major therapeutic approach, not mentioned in the studies, is psychosurgery.

We should like to draw attention to the review of psychosurgery in obsessional disorder (Mindus \& Jenike, 1992). A further important outcome study, conducted from one centre, is provided by Hay et al (1992).

Both papers indicate that psychosurgery, when conducted by present-day stereotactic techniques, retains an important role in the management of severe obsessional disorder resistant to other treatment. It is important to note that the cingulate gyrus lesion does not appear to have advantage over the techniques based on lesion in the fronto-thalamic radiation.

In Britain the procedure based on radioactive induced lesion, known as subcaudate tractotomy is predominant because of the use of this technique at the major national centre. We have adhered to a simpler and more limited approach by a circumscribed stereotactically placed lesion, $9 \mathrm{~mm}$ in diameter, in the fronto-thalamic radiation. An outcome study of our series does not prompt us to abandon the technique (Hay et al, 1993).

Sometimes there seems to be an impression that the Mental Health Commission has virtually banned psychosurgery. This is not the case, although rigorous standards are laid down. In the middle decades of this century vociferous denigration of somatic treatment for psychiatric disorder led to the widespread abandonment of psycho- surgery. Today the ethics should be questioned of withholding information concerning the existence of treatment which has been shown to offer some chance of relief from suffering. Our survey of psychiatric opinion (Snaith et al, 1984) which was undertaken prior to the establishment of the Yorkshire Regional Psychosurgery Service, confirmed that there was a requirement for the service not only for obsessional disorder but also for intractable depressive disorders, and a preference for the regional establishment of such a service.
Hay, P., Sachiev, P., Cumming, S., et al (1993) Treatment of obsessive-compulsive disorder by psychosurgery. Acta Psychatrica Scandinavica, 87, 197-207.
JAMES, I. A. \& BlaCkBURN, I. M. (1995) Cognitive therapy with obsessive-compulsive disorder. British Journal of Psychiatry. 166, 444-450.
Mindus, P. \& JeNIKE, M. A. (1992) Neurosurgical treatment of malignant obsessive-compulsive disorder. Psychiatric Clinics of North America, 15, 921-938.
Piccinelli, E., Pini, S., Bellantuono, C., et al (1995) Efficacy of drug treatment in obsessive-compulsive disorder. A meta- analytic review. British Journal of Psychiatry, 166, 424-443.
SNATth, R. P., Price, D. J. E. \& Wright, J. F. (1984) Psychiatrists' attitudes to psychosurgery. British Journal of Psychiatry, 144, 293-297.

St James's University Hospital

R. P. SNATth

Leeds LS9 $7 T F$

Pinderfields Hospital

D. J. E. PrICE

Wakefield, West Yorks

St James's University Hospital

J. MaRLOWE

Leeds LS9 7TF

\section{Treatment of obsessive-compulsive disorder}

SIR: Piccinelli et al (1995) seem to sideline exposure therapy given to many OCD sufferers in the UK by writing that although behaviour therapy has been reported to be more effective than pharmacological interventions and to provide long-term improvement with low relapse rate, in reality few patients actually undergo this treatment, either as a result of refusing to participate, high cost, andlor lack of qualified behavioural therapists (emphasis added).

The three points in italics deserve correction. First, in controlled studies, OCD patient refusal rates were in fact lower for exposure (behaviour) therapy than for clomipramine. Second, behaviour therapy costs less than medication in the long run as one-off exposure usually produces lasting improvement, whereas medication generally needs to be continued for years to avoid relapse. Finally, there 